\title{
¿Defensa de la Constitución o de la constitucionalidad?
}

\section{Defense of the Constitution or of constitutionality?} 0 (0)

JOSÉ FÉLIX PALOMINO MANCHEGO

Universidad Nacional Mayor de San Marcos

(Lima, Perú)

Contacto: jpalominom@unmsm.edu.pe https://orcid.org/0000-0003-1082-193X

DANTE PAIVA GOYBURU Universidad Nacional Mayor de San Marcos (Lima, Perú)

Contacto: dante.paiva@unmsm.edu.pe https://orcid.org/0000-0001-9140-6580

\section{RESUMEN}

El presente trabajo se centra en el análisis del artículo 38 de la Constitución Política del Perú de 1993, que establece como un deber de todo peruano honrar al Perú, proteger los intereses nacionales, así como el respeto, el cumplimiento y la defensa de la Constitución y el ordenamiento jurídico del país. Se advierte que este último requiere precisión en torno a las instituciones que se protegen, debiendo distinguirse entre la Constitución, como norma de normas, y la constitucionalidad, que representa el principio 
esencial bajo el cual se construyen las democracias modernas. De esta forma, se repasan los mecanismos establecidos para la defensa de la jerarquía normativa de la Constitución, así como la necesidad de forjar una comprometida cultura, patriotismo y un sentimiento constitucional.

Palabras clave: Constitución; sistema democrático; deberes del ciudadano.

\section{ABSTRACT}

This paper focuses on the analysis of article 38 of the Political Constitution of Peru of 1993, which establishes as a duty of all Peruvians to honor Peru, protect national interests, as well as to respect, comply with and defend the Constitution and the country's legal system. It should be emphasized that the latter requires precision as to the institutions it protects, distinguishing between the Constitution, as a rule of rules, and constitutionality, which represents the essential principle under which modern democracies are built. In this manner, the mechanisms established for the defense of the normative hierarchy of the Constitution are reviewed, as well as the need to forge a committed culture, patriotism, and constitutional sentiment.

Key words: Constitution; democratic system; duties of the citizen.

Recibido: 31/05/2021 Aceptado: 08/06/2021

\section{INTRODUCCIÓN}

El bicentenario de la independencia peruana es la oportunidad propicia para reflexionar y formular propuestas que coadyuven a la solución de los problemas que aún se presentan en nuestra realidad. La informalidad, la falta de integración como nación y la 
excesiva indiferencia sobre los asuntos públicos, por mencionar algunos, son flagelos que nos siguen costando la posibilidad de constituirnos plenamente como un Estado con miras al desarrollo y el progreso. En la actualidad incluso más con la pandemia de la COVID-19.

Gran parte de la vida política del país ha sido azarosa. Si bien en el siglo XXI hemos tenido la continuidad de varios gobiernos, conforme a las reglas previstas en la Constitución (sea por sufragio activo o pasivo, o relevo ante vacancias), lo que no se veía desde la República Aristocrática, la sensación de crisis e inestabilidad es una constante, mellando la confianza de la ciudadanía hacia el Gobierno y debilitando la aún endeble democracia. El ánimo ciudadano se puede percibir en el respaldo que tienen partidos políticos sin programa, improvisados o "antisistema», así como en las periódicas protestas que se realizan no solo en las calles, sino también en las redes sociales, que hoy toman un mayor espacio por los niveles de alcance y contacto con los ciudadanos.

¿Qué hacer frente a este descontento? Problemas estructurales como la falta de empleo, la inseguridad ciudadana y la delincuencia, la corrupción, la deficiencia en la prestación de servicios de salud, educación y otros de carácter público, fomentan los reclamos de la población y deben ser atendidos con prioridad y efectividad por parte de las autoridades. No obstante, advertimos que un aspecto se ha descuidado. Se trata de la educación cívica, la adecuada instrucción para que los ciudadanos, desde la escuela, conozcan sus derechos y deberes, así como las competencias y funciones del Gobierno y los deberes que emanan del Estado hacia su población. Los cambios de paradigma en la era digital exigen que la educación sea a tenor del autoaprendizaje.

Una adecuada enseñanza acerca de las instituciones jurídicas elementales, así como el civismo, debe ser una vocación permanente por parte del sistema educativo, apoyándose en la acción 
civil organizada para poder llegar a los mayores espacios posibles. No hay futuro para la patria ni la defensa de los intereses del país sin una nación debidamente educada, que sepa defender a la patria y participar responsablemente en la vida política del país.

Lo expuesto se asocia con lo previsto en el artículo 38 de la Constitución Política del Perú, que establece que «todos los peruanos tienen el deber de honrar al Perú y de proteger los intereses nacionales, así como de respetar, cumplir y defender la Constitución y el ordenamiento jurídico de la Nación» (Congreso Constituyente Democrático, 1993). Sobre esto último, advertimos que se necesita una precisión terminológica acerca de las instituciones que comprende, a efectos de poder instruir adecuadamente a la nación sobre el correcto cumplimiento de este deber.

\section{ENTRE LA CONSTITUCIONALIDAD Y LA CONSTITUCIÓN}

A la luz de la normatividad constitucional de 1993, el artículo referido emplaza al respeto, el cumplimiento y la defensa de la Constitución. En este sentido, se establecen de manera textual los alcances del deber de todos los peruanos hacia la norma fundamental. No obstante, consideramos pertinente hacer una atingencia en torno al alcance y sentido de dicho artículo, por cuanto propugnamos que debe tutelarse y garantizarse la constitucionalidad del sistema jurídico y que los ciudadanos deben velar por esta.

A partir de lo anterior resulta oportuno distinguir la diferencia entre constitucionalidad y Constitución. La primera hace referencia a la condición de vivir conforme a los mandatos y el pacto político que representa la norma suprema, lo cual involucra los fines de la sociedad y el Estado, la organización y estructura de este, así como el respeto a los derechos fundamentales, y también supone que aquellas sociedades que no cuentan con la norma escrita pueden asociarse con el sentido material de Constitución. En el caso de la 
segunda, tomando la perspectiva de la Constitución en el sentido formal, esta hace referencia al contenido o texto de la norma jurídica cuya aplicación se realiza de acuerdo con sus disposiciones textuales o interpretativas.

Ahora bien, el respeto, la defensa y el cumplimiento de la Constitución a los que hace referencia el artículo 38 deberían entenderse como una invocación a la protección y observancia del Estado constitucional, es decir, la actuación en el marco del principio de constitucionalidad, procurando que las acciones de gobernantes y gobernados se sustenten en los valores que encarna la norma fundamental. Esto implica que las medidas políticas y la acción civil no deben atentar contra el marco establecido, y que debe guardarse la debida observancia de los mandatos constitucionales. Asimismo, para una garantía jurisdiccional de la norma fundamental, teniendo en cuenta la categoría desarrollada por Hans Kelsen, contamos con procesos de control normativo, tales como el proceso de inconstitucionalidad y el proceso de acción popular, los cuales son competencia del Tribunal Constitucional y el Poder Judicial, respectivamente.

\section{LOS MECANISMOS DE DEFENSA DE LA CONSTITUCIÓN COMO NORMA SUPREMA}

Conforme planteamos, no debe confundirse la defensa de la constitucionalidad del sistema jurídico, que debe afirmarse mediante el deber previsto en el artículo 38 de la Constitución, con la defensa de la norma suprema, la cual tiene mecanismos específicos para su tutela, como vienen a ser, por ejemplo, los procesos constitucionales.

En su noción general, los procesos constitucionales, que suman siete, conforme a lo señalado en el Código Procesal Constitucional de 2004, se clasifican en procesos de tutela de derechos (habeas 
corpus, habeas data, amparo y cumplimiento), procesos de control normativo (acción popular y de inconstitucionalidad) y el proceso de conflicto de competencias (competencial). Indudablemente, en el caso de los procesos de control normativo, la razón principal es la protección jurídica de la primacía de la Constitución respecto de las leyes o normas con rango de ley, en concordancia con lo dispuesto en el artículo 51 de la norma fundamental, para el caso del proceso de inconstitucionalidad. Mientras que la primacía de la Constitución y la ley respecto del resto de normas de rango inferior a ley puede tutelarse mediante el proceso de acción popular.

De esta suerte, todo estudio en torno al proceso de inconstitucionalidad debe llevarnos, necesariamente, a revisar «La garantía jurisdiccional de la Constitución (la justicia constitucional)», célebre estudio de Hans Kelsen (2017), en el cual refirió, acerca del control de constitucionalidad, lo siguiente:

El órgano legislativo se considera en la realidad como un libre creador del Derecho y no como un órgano de aplicación del Derecho vinculado a la Constitución, no obstante que lo está, teóricamente, bien que en una medida relativamente reducida.

No es pues el Parlamento mismo con quien se puede contar para realizar su subordinación a la Constitución. Es un órgano diferente a él, independiente de él, y por consiguiente, también de cualquier otra autoridad estatal, al que es necesario encargar la anulación de los actos inconstitucionales - esto es, a una jurisdicción o Tribunal Constitucional- (p. 72).

En torno a la propuesta de Kelsen, el maestro Domingo García Belaúnde considera:

En realidad, lo que sostiene Kelsen en su sugestiva ponencia es, aparte de detalles que son de indudable atractivo, dos aspectos básicos: lo primero es que la Constitución tiene un valor jurídico y no político. Y lo segundo es, que siendo jurídica la Constitución, 
hay que tener presente la posibilidad de que ella sea alterada o desconocida por los operadores o destinatarios del poder, y en consecuencia tiene que existir un órgano ad hoc que sea el vigilante de la Constitución y el que sancione las infracciones que atenten contra ella (Kelsen, 2017, p. 237).

Ahora bien, un concepto que podemos dar en torno a este proceso, sobre la base de lo dispuesto en la Constitución y el Código Procesal Constitucional, es que se trata de una garantía constitucional mediante la cual se ejerce un control normativo de carácter concentrado, que tiene por objeto defender la Constitución frente a infracciones contra su jerarquía normativa por parte de normas que tienen rango de ley.

\section{PATRIOTISMO, CULTURA Y SENTIMIENTO CONSTITUCIONAL}

En lo tocante a este segmento, debemos precisar algunos conceptos. En efecto, las categorías que presentamos en esta parte se relacionan con el deber de defensa de la constitucionalidad, sobre el cual venimos abogando, y es que, como podrá apreciarse, el patriotismo, la cultura y el sentimiento constitucional resultan elementos esenciales para garantizar la viabilidad del Estado constitucional, toda vez que inciden en la formación de los ciudadanos y su responsabilidad en la sostenibilidad de un grupo humano organizado, jurídica y políticamente subsistente. La derivación lógica de lo anterior supone el imperio de la ley, que estableció una nueva forma de organización política con el propósito de lograr una sociedad más ordenada y segura. Naturalmente, y como es propio de todo fenómeno, se atraviesan distintas etapas, sobre todo por la reacción de la masa que, al no entender los cambios, y ante el temor por estos, mira con desconfianza lo nuevo. Ese paradigma, que no ha estado exento de cuestionamientos y alternativas, predomina aún en el mundo occidental del primer tercio del siglo XXI. 
De esta forma, el Estado de derecho ha procurado consolidarse como el sistema que rompe con la arbitrariedad del Antiguo Régimen, y también ha tenido que perfeccionarse para asegurar un propósito mayor, nada sencillo, pero indispensable para todo Estado constitucional: la defensa de la persona humana y el respeto a su dignidad, aspecto sobre el cual la evolución de los derechos humanos, y su incorporación en los distintos sistemas jurídicos del mundo (control de convencionalidad), juega un trascendental papel.

Ahora bien, la garantía sobre los derechos, su fomento y su protección implican un esfuerzo constante por parte del Gobierno. Esta visión general la concebimos a partir de lo sancionado en la Declaración de Derechos del Buen Pueblo de Virginia (ratificada el 12 de junio de 1776), que prescribe lo siguiente:

III. Que el gobierno es instituido, o debería serlo, para el común provecho, protección y seguridad del pueblo, nación o comunidad: que de todas las formas y modos de gobierno, es el mejor, el más capaz de producir el mayor grado de felicidad y seguridad, y el que está más eficazmente asegurado contra el peligro de un mal Gobierno; y que cuando un Gobierno resulte inadecuado o es contrario a estos principios, una mayoría de la comunidad tiene el derecho indiscutible, inalienable e irrevocable de reformarlo, alterarlo o abolirlo de la manera que se juzgue más conveniente al bien público.

Tal como puede apreciarse, el propósito irrenunciable que debe guiar a todo gobierno es la búsqueda del bienestar de su nación, asegurando su pleno desarrollo en libertad, garantizando una adecuada convivencia e inyectando prácticas globales para la educación mediante las políticas públicas. Un descuido sobre esta meta a seguir no hace más que devaluar al gobierno y defraudar la confianza en el sistema democrático, más todavía cuando trasunta en los servicios que son sinónimo de cultura. 
Aun así, resulta pertinente considerar que no todos los ciudadanos o integrantes de la nación acatan plena y automáticamente las decisiones del gobierno, y tampoco tendrían por qué hacerlo así de sencillo. El libre albedrío busca prevalecer frente a todo aquello que se considere un obstáculo. Sin embargo, se debe advertir que la cuarentena y la aparición del coronavirus plantean una revisión total del servicio educativo mediante soportes tecnológicos. Y la cultura, in genere, no puede perjudicarse.

Así, urge sustentar el poder. $\mathrm{Al}$ romper con el paradigma anterior, del uso de la fuerza y el miedo a preservar un gobierno a partir del temor de los súbditos, los Estados constitucionales tienen la obligación de consolidarse a partir de la creencia y los valores infundidos en la población, mediante la enseñanza y el ejemplo, de que los actos que desarrolla el gobierno buscan asegurar el crecimiento y el bienestar de la gente. En tal sentido, Maurice Duverger (1970) sostiene que:

La definición de la legitimidad del poder [político] reposa en un sistema de valores. Los sistemas de valores sirven para justificar las reglas de conducta propuesta como modelos a los miembros de la sociedad. En la medida en que los individuos creen en el sistema de valores de la sociedad en que viven, obedecen sus reglas porque las consideran buenas. El sentimiento de deber moral es así la otra base de la obediencia de las reglas (p. 34).

A partir de lo señalado, en la cotidianidad política de las últimas décadas se han forjado categorías asociadas a reforzar la cuestión axiológica sobre el Estado constitucional, con el fin de instruir a la sociedad, principalmente a la masa, sobre las ventajas y los beneficios que surgen de un orden institucionalizado, y los mecanismos para asegurar su sostenimiento, entre los que podemos destacar el «patriotismo constitucional», la «cultura constitucional» y el «sentimiento constitucional». 
En relación con el «patriotismo constitucional», cabe recordar que su origen se ubica en 1970, propiamente el Verfassungspatriotismus, expuesto por el politólogo germano Dolf Sternberger, recogido y difundido luego por Jürgen Habermas, con una visión integradora del pueblo en los valores que expresa la ley fundamental.

A su vez, sobre este concepto, Gregorio Peces-Barba (2003) ha referido lo siguiente:

La cultura constitucional y la idea de la constitución como vida conducen a la idea de patriotismo constitucional, que supone un añadido, una adhesión mayor que la simple aceptación de los valores y de las reglas de juego constitucionales y que la misma idea de lealtad a la Constitución. Constituye a esos valores y a esas reglas en la razón de ser de la convivencia, que se vive y se interioriza por los participantes en el sistema. Es la razón central del pacto social, la razón central por la cual se integran en ese pacto los ciudadanos y por la cual convierten a la constitución en el referente de la vida en común (p. 40).

En el concepto de patriotismo constitucional se encuentra la tradición republicana, desde Roma, con Cicerón y su idea de la libertad dependiente de la Ley, hasta Rousseau y Kant pasando por Maquiavelo, los humanistas del Renacimiento, Montesquieu o Voltaire que es también la de Habermas (p. 50).

Por su parte, Carlos Ruiz Miguel (2004) sostiene, acerca de esta categoría:

el «patriotismo constitucional» y la «defensa de la Constitución» se hallan estrechamente ligados. Solo el primero puede hacer efectiva la segunda. Mientras el primero previene los ataques a la Constitución, la segunda los reprime. Ahora bien, la mera represión de los ataques a la Constitución no resulta suficiente cuando las causas de la desestabilización siguen existiendo (p. 91). 
Respecto de la «cultura constitucional», uno de sus principales difusores es Peter Häberle (2002), quien ha señalado sobre esta categoría lo siguiente:

La Constitución no es solamente un texto jurídico ni tampoco una acumulación de normas superiores, es también expresión de un estado de desarrollo cultural, un medio de autorrepresentación de un pueblo, un espejo de su herencia cultural y un fundamento de sus nuevas esperanzas. Las Constituciones vivas son la obra de todos los intérpretes constitucionales de la sociedad abierta; son, por su forma y razón de ser, de largo, una expresión y mediación cultural, un cuadro para la reproducción y recepción y un almacén de información, experiencias, aventuras y hasta de sapiencias «culturales» transmitidas (p. 194).

Considerando una posición similar, pero desde el constitucionalismo iberoamericano, Néstor Pedro Sagüés (2010) reflexiona conforme se expone a continuación:

Una constitución sin una base cultural constitucional mínima a) en sus autores, b) en sus operadores fundamentales y c) en el pueblo al que va destinada es una constitución destinada al fracaso. En rigor de verdad, esa dosis de cultura constitucional, más que un adorno del sistema, es un presupuesto de su funcionalidad. Tal cultura constitucional requiere que la constitución cumpla con una cuota indispensable de buena técnica, razonabilidad y consenso. Por ello, no es acertado que sea utópica, copista ni elefantiásica (p. 106).

Mientras que, en una fecha más reciente, Lucio Pegoraro (2019) ha afirmado:

«Cultura constitucional» es la cultura jurídica que acepta, vive, venera la superioridad de la constitución, pero no cualquier constitución, sino solo la que acepta la división de poderes (poco) y sobre todo los derechos humanos, en sus interpretaciones más radicales hasta rechazar la democracia, la voluntad popular, el 
Estado, el propio Estado de Derecho, confiando en un poder -el judicial y de control de la constitucionalidad, estructurado en los siglos pasados para proteger estos valores-, para imponer un «núcleo ético esencial» que orienta esos valores, los limita y a veces incluso los anula (pp. 22-23).

En relación con el sentimiento constitucional, advertimos que el germen de esta categoría se encuentra en la obra de Karl Loewenstein (1982), quien en su Teoría de la Constitución le dedica un acápite, donde resalta que

con la expresión «sentimiento constitucional» (Verfassungsgefühl) se toca uno de los fenómenos psicológicos sociales y sociológicos del existencialismo político más difíciles de captar. Se podría describir como aquella conciencia de la comunidad que trascendiendo a todos los antagonistas y tensiones existentes políticospartidistas, económicosociales, religiosos o de otro tipo, integra a detentadores y destinatarios del poder en el marco de un orden comunitario obligatorio, justamente la constitución, sometiendo el proceso político a los intereses de la comunidad. [...] la formación del sentimiento constitucional depende ampliamente de los factores irracionales, de la mentalidad y la vivencia histórica de un pueblo, especialmente de si la constitución ha salido airosa también en épocas de necesidad nacional. El sentimiento constitucional no puede ser explicado exclusivamente por la longevidad de una constitución (p. 200).

El alcance de esta categoría ha sido relevante (García, 2010, pp. 549-550). A lo propuesto por Loewenstein se han sumado las contribuciones de Pablo Lucas Verdú, Javier Tajadura Tejada, Gerardo Eto Cruz, entre otros. Al respecto, este último sostiene que

a la larga, el sentimiento constitucional va a constituirse en un modo de integración política dentro de un Estado Social y Constitucional de Derecho; y ello permitirá que, en los momentos de mayor crisis institucional, una cultura constitucional de adhesión genere 
la estabilidad de todo el sistema político. Sin embargo, esta adhesión no se da gratuitamente, sino que va indefectiblemente ligada a las conductas reales y concretas de los detentadores del poder; a su lealtad a los valores constitucionales y a los contenidos esenciales de lo que tradicionalmente podemos identificar como los contenidos esenciales del respeto a los derechos fundamentales de las personas, tanto como el respeto de la parte orgánica de la Constitución (Eto, 2008, p. 375).

De esta forma se menciona al sentimiento constitucional como un aspecto esencial para asegurar la consolidación y el mantenimiento del sistema vigente, esto es, la democracia y la forma republicana de gobierno, sin perjuicio de las mejoras necesarias que corresponda implementarse. Así, Ernesto Blume (2019) ha referido que

en armonía con las tareas jurisdiccionales y de docencia constitucional que nos corresponden, inspiradas en la idea de difundir lo constitucional en aras de sembrar y forjar un verdadero sentimiento constitucional, que garantice una conciencia firme y segura en el pueblo del significado, el valor y la importancia de nuestra Constitución y del sistema constitucional peruano, así como del rol del Tribunal Constitucional (p. 6).

Debe considerarse, también, que al ser el sentimiento una categoría propia del ánimo, individual o colectivo, su explicación implica aspectos éticos y espirituales que resultan algo complejos de definir en su estructuración, así como la forma de fomentarlo dentro de la población.

\section{LA VISIÓN DEL SENTIMIENTO CONSTITUCIONAL EN EL PERÚ BICENTENARIO}

Hace poco más de un siglo, Víctor Andrés Belaúnde (1994) sentenciaba lo siguiente respecto de nuestra realidad como sociedad: 
Necesitamos robustecer el sentimiento nacional, esto que se llama el alma nacional, y que solo formará la universidad el día que estudie nuestra geografía y nuestra historia política y económica, más seriamente y por medio de las disciplinas especiales. Nuestro sentimiento nacional es débil, porque no queremos la tierra, ni tenemos culto a los muertos. Marchamos distraídos y solos. Somos desarraigados (p. 164).

El reclamo de Belaúnde sobre el espíritu nacional fue un quehacer permanente en toda su obra. Estudiando detalladamente los orígenes y las posibilidades de la patria, se entiende que esta no alcanzaría sus propósitos si no desarrollaba un auténtico amor por el Perú, para lo cual se necesitaba el impostergable esfuerzo de la universidad, así como de la educación en general, lo que permitiría mejorar la autoestima y la identificación con nuestra tierra. Precisamente, años más tarde nos diría:

En síntesis: la educación patriótica y cívica no solo debe comprender una lista de deberes y una serie de actos que las completen sino la visión amorosa y profunda de la realidad nacional, el señalamiento de las esencias y de las categorías peruanistas que den a la juventud la clara visión de la Patria y de sus gloriosos destinos (Belaúnde, 1983, p. 448).

Su visión incidía sobre el sentimiento nacional en general, analizando una situación que, al siglo XXI, parece no haber variado mucho, teniendo en cuenta, además, que la tan anhelada educación patriótica hoy está por otra vertiente, donde el curso de Educación Cívica prácticamente ha desaparecido y la informalidad predomina en muchos niveles y relaciones.

Ante este panorama, en el que la conciencia nacional se encuentra a medio hacer y el excesivo culto al individualismo ha frustrado el desarrollo de un alma nacional, es evidente que no existe un suelo fértil para que el sentimiento hacia nuestras instituciones 
cale con profundas y sólidas raíces y, más bien, se repulse el orden normativo y los propósitos nacionales que corresponde asegurar mediante el sistema jurídico y el trabajo de las autoridades. Sobre este punto, Víctor García Toma (2010) ha referido lo siguiente:

El constitucionalismo peruano como promesa nacional - tomando la feliz expresión de Jorge Basadre- jamás afrontó los problemas de la segmentada y jerarquizada sociedad nacional, ni atacó programáticamente la distribución desigual de la riqueza. La retórica constituyente vació de contenido los principios y valores de la democracia (p. 556).

Sobre ello, consideramos que el constitucionalismo peruano ha tenido importantes avances y un desarrollo consistente en lo que corresponde al cultivo de la ciencia constitucional, llegando a posicionarse en un expectante lugar dentro del ámbito académico de Iberoamérica (Paiva, 2020). Sin embargo, en lo que concierne al respeto del Estado constitucional, este se ha visto amenazado y vulnerado por la acción de nefastos personajes en la política, quienes se abren paso ante una sociedad en la que los valores constitucionales tienen exigua enseñanza hacia la población, en la que los hogares y las escuelas no llegan a cumplir su rol esencial en este extremo.

Aun con los continuos quebrantamientos al orden institucional que han ocurrido en nuestro país, cabe señalar que, en ocasiones excepcionales, el sentimiento se ha manifestado súbitamente. Así, Valentín Paniagua, al momento de asumir la presidencia de la República el 22 de noviembre de 2000, sostuvo que «por extraño que parezca, son sentimientos nacidos de una profunda convicción nacional: la necesidad de exaltar, afirmar y consolidar la Constitución como norma de vida y de convivencia diaria» (2000, p. 1).

Consideramos clave para el adecuado desarrollo de una sociedad que todos los miembros de la nación cumplan con su deber. 
Destacamos al respecto que, con el corto período que tenía el gobierno de transición a su cargo, el recordado expresidente Valentín Paniagua adoptó acciones para mejorar la calidad de la Constitución vigente, sumamente venida a menos por el actuar del gobierno que impulsó su establecimiento en 1993, y para ello convocó una Comisión de Estudio de las Bases para la Reforma Constitucional, integrada por personalidades comprometidas con ese noble propósito. El día en que este grupo presentó su informe, Valentín Paniagua (2001) esbozó algunas razones sobre el errante devenir de nuestra evolución política:

Ahí está, aun incumplida, la promesa republicana que puede y debe traducirse en un Estado de Derecho equilibrado, dinámico y comprometido con los valores inherentes a la dignidad de la persona humana. Es inaplazable, a las alturas del tercer milenio, la creación de igualdad de oportunidades económicas y sociales, para todos, a fin de enfrentar los desafíos de la sociedad y de la revolución del conocimiento. Está, en suma, el reclamo de democracia y paz para una sociedad ansiosa de reconciliarse consigo misma y con su irrenunciable destino histórico de libertad y de justicia (p. 11).

\section{REFLEXIONES FINALES}

A modo de visión panorámica, presentamos las siguientes conclusiones: el nuevo milenio representó una oportunidad para superar esas tendencias hacia la autocracia, que fueron continuas en gran parte de nuestra vida republicana. Sin embargo, con los años, los procesos seguidos contra todos los expresidentes involucrados en serias denuncias por casos de corrupción y enriquecimiento indebido, por mencionar solo algunos cargos, que llevaron incluso a que se dicten medidas de prisión, fueron una afrenta ante el país porque se valieron del cargo confiado para quebrantar la ley. 
Frente a ello, el sentimiento constitucional —es justo decirlose ve inevitablemente mermado porque la esencial confianza que deben tener los ciudadanos hacia las instituciones no se ve correspondida con un trabajo honesto que tenga como prioridad el desarrollo del país, el cual se basa en el bienestar y la conducción sensata de la nación. Así, ese sentimiento queda como una de las tantas promesas pendientes en el país, que se ha visto frustrada de emerger ante tanta decepción y mediocridad.

En este sentido, sobre el valor de nuestras propias vivencias y la lección que estas nos dejan, es propicio invocar las clásicas palabras de Ortega y Gasset (1941):

Porque no puede aclararse el ayer sin el anteayer, y así sucesivamente. La historia es un sistema - el sistema de las experiencias humanas, que forman una cadena inexorable y única-. De aquí que nada pueda estar verdaderamente claro en historia mientras no está toda ella clara (p. 67).

Todo esto confirma que patriotismo, cultura y sentimiento constitucional, conforme a lo que hemos desarrollado en el acápite pertinente, son categorías con una infatigable búsqueda en la cual la educación juega un papel crucial para su desarrollo, y donde los hogares, las escuelas y las universidades asumen un rol preponderante. El producto final tiene que ser, sin mengua, el ciudadano responsable, para lo cual se tiene que trabajar denodadamente con el propósito de asegurar a las nuevas generaciones.

Como es lógico, el patriotismo constitucional involucra un ánimo superior de plena confianza en la Constitución como norte en la vida común, no necesariamente porque esta sea un producto perfecto, sino porque los valores que la inspiran reafirman la voluntad de vivir como sociedad y establecerse bajo los cánones de la tradición republicana. Este patriotismo, indispensable en los momentos álgidos, infunde valentía para hacer prevalecer la 
Constitución, alentando el deber de defenderla ante las amenazas de las arbitrariedades y procurando dar solución definitiva a las razones que la originaron, para desterrar esas amenazas de raíz.

Por su parte, la cultura constitucional es una vocación permanente que debe ser especialmente asumida por el constituyente (originario y derivado) y por todos aquellos cuyo trabajo los vincula con los quehaceres políticos del país, sobre todo las autoridades, los abogados y los jueces. En su más amplio sentido, esta cultura implica un infatigable aprendizaje, muchas veces autodidacta, de los personajes convocados, inspirados en el cumplimiento de su rol histórico y social, porque la posición que asumen como profesionales y autoridades les exige un deber mayor, comprometido con las causas justas y la protección del sistema democrático.

Con este fin, la cultura constitucional debe ser un elemento recurrente en toda autoridad y profesional del derecho, que nutra también su conciencia en el desarrollo del rol que ocupa, para que anteponga, frente a toda tentación mundana material, los intereses de una sociedad que deposita la confianza en un sistema en el que la verdad y la justicia son el patrimonio más valioso, y que el cuidado de estos sea el que guíe sus actos, asegurando el sostenimiento del Estado para que este siga brindado oportunidades a quienes están y a quienes vendrán.

Convendría decir, por tanto, que el sentimiento constitucional no surge de forma automática. Es el resultado de la suma de experiencias de cada ciudadano, y la convicción de que las instituciones en la sociedad donde se desenvuelve garantizan la libertad y el respeto de los derechos fundamentales gracias a la Constitución como norma suprema. Para tal efecto, junto con la educación cívica constante en los hogares, las escuelas y las universidades, el ejemplo y el compromiso de las autoridades coadyuvan a que aflore este sentimiento, que, idealmente, debería estar presente cada día en la mente de todos los peruanos. 
Para este propósito es indispensable asumir, como compromiso por el bicentenario, una acción más efectiva por parte de los agentes involucrados. Reiteramos: el sentimiento es algo que surge desde la propia persona, no puede ser impuesto el afecto hacia el mismo. No obstante, mediante la enseñanza sí puede instruirse sobre el valor de la democracia y la preservación del Estado social y democrático de derecho. Como tal, es preciso convocar la acción efectiva y la responsabilidad social de las universidades y los colegios de abogados del país, para que en forma conjunta con las autoridades nacionales, regionales y locales puedan complementar esa tarea pendiente en la formación cívica y preparar, así, el terreno para que el sentimiento constitucional encuentre el espacio fértil para su desarrollo.

A fin de cuentas, los elementos analizados permitirán instruir adecuadamente a la población en el cumplimiento de su deber, esto es, que sean capaces, tanto en el desarrollo de su vida diaria como cuando corresponda denunciar el oprobio, de defender de manera responsable la constitucionalidad del sistema jurídico, rechazando cualquier iniciativa, cualquiera sea la fuente de donde provenga, que ponga en riesgo la institucionalidad y la libertad.

\section{REFERENCIAS}

Belaúnde, V. A. (1983). Peruanidad (5. ${ }^{\mathrm{a}}$ ed.). Banco Central de Reserva del Perú/Fondo del Libro del Banco Industrial del Perú.

Belaúnde, V. A. (1994). La crisis presente. 1914-1939 (6. a ed.). Luis Alfredo Ediciones.

Blume, E. (2019). Discurso del presidente del Tribunal Constitucional del Perú, magistrado Ernesto Blume Fortini, en la ceremonia de celebración del vigésimo tercer aniversario institucional. https://tc.gob.pe/publicaciones/resumenes/2019/junio/Discurso \%20de\%2023\%20aniversario\%20TC.pdf 
Congreso Constituyente Democrático (1993). Constitución Política del Perú. Lima: 31 de octubre de 1993.

Duverger, M. (1970). Instituciones políticas y derecho constitucional (5. ${ }^{\mathrm{a}}$ ed.). Ariel.

Eto, G. (2008). Sobre el sentimiento constitucional peruano. En Cáceres, J. (ed.), Ponencias desarrolladas. IX Congreso Nacional de Derecho Constitucional. Adrus.

García Belaúnde, D. (2017). Kelsen en París: una ronda en torno al «modelo concentrado». En Kelsen, H., Sobre la jurisdicción constitucional (pp. 223-246). Universidad Inca Garcilaso de la Vega.

García Toma, V. (2010). Teoría del Estado y derecho constitucional (3. ${ }^{\mathrm{a}}$ ed.). Adrus.

Häberle, P. (2002). La Constitución como cultura. Anuario Iberoamericano de Justicia Constitucional, (6), 177-198.

Kelsen, H. (2017). La garantía jurisdiccional de la Constitución (la justicia constitucional). Sobre la jurisdicción constitucional (pp. 39-106). Universidad Inca Garcilaso de la Vega.

Loewenstein, K. (1982). Teoría de la Constitución (2. a ed.). Ariel.

Ortega y Gasset, J. (1941). Historia como sistema y del Imperio romano. Revista de Occidente.

Paiva, D. (2020). Del movimiento constitucional peruano a la Escuela Peruana de Derecho Constitucional. Grijley.

Paniagua, V. (2000). Mensaje del presidente constitucional del Perú, doctor Valentín Paniagua Corazao, ante el Congreso Nacional, el 22 de noviembre de 2000. http://www.congreso. gob.pe/participacion/museo/congreso/mensajes/mensajecongreso-22-11-2000/ 
Paniagua, V. (2001). Discurso pronunciado en la ceremonia de entrega del informe de la Comisión de Estudio de las Bases para la Reforma Constitucional. En Ministerio de Justicia, Comisión de Estudio de las Bases de la Reforma Constitucional del Perú. Konrad Adenauer Stiftung.

Peces-Barba, G. (2003). El patriotismo constitucional. Reflexiones en el vigésimo quinto aniversario de la Constitución española. Anuario de Filosofía del Derecho, (20), 39-61.

Pegoraro, L. (2019). Constitucionalización del derecho y cultura constitucional. Revista de Derecho Político, (104), 13-57.

Ruiz, C. (2004). Patriotismo constitucional. Cuadernos de Pensamiento Político, (3), 81-92.

Sagüés, N. (2010). Cultura constitucional y desconstitucionalización. Anuario de Derecho Constitucional Latinoamericano, año XVI, 97-108. Konrad Adenauer Stiftung. 